\title{
Selection pressures have driven population differentiation of domesticated and wild common carp (Cyprinus carpio L.)
}

\author{
L.H. Xu' ${ }^{1}$, C.H. Wang ${ }^{1}$, J. Wang ${ }^{1}$, Z.J. Dong ${ }^{2}$, Y.Q. Ma ${ }^{1}$ and X.X. Yang ${ }^{1}$ \\ ${ }^{1}$ Key Laboratory of Aquatic Genetic Resources and Utilization, \\ Ministry of Agriculture, Shanghai Ocean University, Shanghai, China \\ ${ }^{2}$ Freshwater Fisheries Research Center, Chinese Academy of Fisheries Science, \\ Wuxi, Jiangsu, China \\ Corresponding author: C.H. Wang \\ E-mail: wangch@shou.edu.cn
}

Genet. Mol. Res. 11 (3): 3222-3235 (2012)

Received October 13, 2011

Accepted May 26, 2012

Published September 12, 2012

DOI http://dx.doi.org/10.4238/2012.September.12.5

\begin{abstract}
Selection pressures are the principle evolutionary forces for the genetic differentiation of populations. Recent changes in selection pressures on mitochondrial DNA and microsatellite have been described in a wide variety of organisms. The common carp (Cyprinus carpio) has experienced strong selection pressure, in particular artificial selection, during its domestication. However, the contribution and extent of artificial selection in driving genome-wide population differentiation remain unclear. We investigated the genetic differentiation of 4 domesticated strains (Xingguo red common carp, Glass red common carp, Purse red common carp, and Jian common carp, which have been generated by artificial selection since 1970s) and 2 wild populations (Shishou section in Hubei and Yangzhou section in Jiangsu of the Yangtze River) of common carp in China by sequencing the mitochondrial DNA D-loop and by genotyping 10 microsatellite loci. It was found that the domesticated strains exhibited linkage disequilibrium within the population and less genetic variability, higher
\end{abstract}


inbreeding coefficients $\left(F_{\text {IS }}=0.101\right.$ vs 0.038$)$, and higher genetic differentiation $\left(F_{\mathrm{ST}}=0.087 \mathrm{vs} 0.001\right)$ than the wild populations, which indicates strong selection pressures in the process of domestication. Of the 10 loci, 5 appeared to be under positive directional selection in the domesticated strains, and all 10 loci in wild populations were potentially under balancing selection. We conclude that strong selection pressures, artificial selection in particular, have caused genetic differentiation between populations of domesticated and wild common carp.

Key words: Cyprinus carpio L.; Genetic differentiation; mtDNA; Microsatellite; Selection pressure

\section{INTRODUCTION}

Artificial selection is believed to be the main evolutionary force acting on domesticated species. During domestication, human exercised extremely strong selective pressure on ancestral gene pools to achieve the desired phenotypic characteristics (Innan and Kim, 2004). However, artificial selection, which is considerably different from natural selection, acts on alleles that would have been neutral or nearly neutral before domestication. As a consequence, artificial selection alters the allele frequency spectrum, reduces the genetic diversity within domesticated species, and increases the genetic divergence between domesticated species. Therefore, the patterns of genetic diversity between populations are often used to detect loci under selection pressure in genome scans (Excoffier et al., 2009). Many studies have been published on how artificial selection affects genetic diversity (Innan and Kim, 2004; Carlson et al., 2007).

The common carp (Cyprinus carpio L.), one of the most widely distributed and important freshwater fishes in the world, is also the longest cultured and the most domesticated fish species in the world (Balon, 1995). In its long history of domestication, numerous strains and variants have been developed from the wild ancestor by means of artificial selection accompanied by natural selection and mutation (Wang et al., 2010). Therefore, the common carp represents an optimal model organism to study the artificial selection signature of the target genes or genomic regions involved in the process of domestication. However, no study has focused on the contribution and extent of artificial selection in the genome-wide population differentiation of this species.

In the process of domestication of the common carp, the forces of selection, founder effects, and genetic drift have resulted in low genetic diversity within the domesticated population and high genetic differentiation between domesticated populations (Kohlmann et al., 2005; Chistiakov and Voronova, 2009; Wang et al., 2010). Loss of genetic diversity in domesticated strains and the effects of these strains on wild populations are of great concern to aquaculture (Wang et al., 2010). The possible genetic consequences of domesticated escapees are the reduction of fitness, disruption of local adaptation, and introgression in the wild by introduction of maladaptive gene complexes (McGinnity et al., 2003; Fraser et al., 2008). Thus, analyses of domestication-induced genetic changes are of great importance to conservation biology.

In recent years, selection pressures on mitochondrial DNA have been widely reported (Bazin et al., 2006; Galtier et al., 2009). On the other hand, a neutral microsatellite may show apparent selective effects if it is in linkage disequilibrium (LD) with another locus subject to 
selection (Barker et al., 2009), i.e., the hitchhiking phenomenon. In this study, we analyzed the mitochondrial D-loop sequences and 10 microsatellites loci from 4 domesticated strains and 2 wild populations. The aims of the present study were to investigate the extent of population genetic differentiation in the domesticated and wild common carps driven by selection pressures and to detect if any of the microsatellite loci show artificial selection sweeps.

\section{MATERIAL AND METHODS}

\section{Sample collection}

The fingerling specimens of 4 famously domesticated strains of common carp, which have been generated by artificial selection since 1970s, were sampled in 2008. Xingguo red common carp (XG), sampled from the National Farm of Xingguo Red Common Carp in Jiangxi Province, China, were of the 18th generation. Glass red common carp (WA), collected at the Provincial Farm of Glass Red Common Carp in Jiangxi Province, China, belonging to the 16th generation. Pursed red common carp (PR), sampled from the National Farm of Pursed Red Common Carp in Jiangxi Province, China, were of the 18th generation. Jian common carp (JIAN), at the 13th generation, were obtained from the Freshwater Fisheries Research Center of Chinese Academy of Fisheries in Jiangsu Province, China. XG, WA and PR are variants of wild common carp differing in body color pattern (Lou and Sun, 2001), while JIAN is a combined breeding strain obtained by crossing the families of the PR and Yuanjiang wild common carp (Zhang and Sun, 2006). These 4 domesticated strains are distributed in the Yangtze River drainage and have been continuously subjected to selection on the basis of growth rate since the 1970s. Additionally, 2 wild populations were collected in the downstream reach (Yangzhou in Jiangsu, YZD) and middle-stream reach (Shishou in Hubei, YZM) of the Yangtze River. The sample sizes of each population are listed in Table 1.

\section{Mitochondrial DNA sequencing and analysis}

Total DNA was extracted following the phenol-chloroform procedure (Sambrook and Russell, 2001). The mitochondrial DNA (mtDNA) D-Loop (DL) region was amplified by polymerase chain reaction (PCR) with primers DL-F (5'-ACC CCT GGC TCC CAA AGC-3') and DL-R (5'-ATC TTA GCA TCT TCA GTG-3'). The reactions were performed in an Eppendorf thermocycler (Eppendorf, Germany) in $50 \mu \mathrm{L}$ volumes containing $25 \mu \mathrm{L}$ PCR master $\operatorname{mix}\left(0.2 \mu \mathrm{M}\right.$ dNTPs, $1.5 \mu \mathrm{M} \mathrm{MgCl}_{2}, 0.5 \mu \mathrm{M}$ Taq DNA polymerase), $3 \mu \mathrm{L}$ template DNA (20 $\mathrm{ng} / \mu \mathrm{L}), 4 \mu \mathrm{L}$ primers $(0.5 \mu \mathrm{M}$ each), and $18 \mu \mathrm{L}$ distilled water. The amplification conditions were initial denaturation at $94^{\circ} \mathrm{C}$ for $5 \mathrm{~min}$, followed by 40 cycles of $94^{\circ} \mathrm{C}$ for $30 \mathrm{~s}, 52^{\circ} \mathrm{C}$ for $30 \mathrm{~s}$, and $72^{\circ} \mathrm{C}$ for $1 \mathrm{~min}$, and a final extension at $72^{\circ} \mathrm{C}$ for $10 \mathrm{~min}$. Agarose gel electrophoresis was used to verify whether PCR amplification was successful. All successfully amplified products were purified using the PCR Product Purification Kit (Tiangen, China), according to manufacturer instructions. The purified products were bidirectionally sequenced on an Applied Biosystems ABI 3730 capillary sequencer using the same PCR primers.

Genomic sequences were edited using BioEdit (Hall, 1999), aligned using ClustalW with default parameters, and checked by eye. Identical sequences and haplotypes were found and collapsed using Collapse v1.2 (Posada, 2006). Population genetic variation, expressed as 
the number of polymorphic sites $(S)$, haplotype diversity $(h)$ (Nei, 1987), and nucleotide diversity $(\pi)$ (Cheng et al., 2009), was estimated using Arlequin 3.5 (Excoffier and Lischer, 2010). Population pairwise $F_{\mathrm{ST}}$ and analysis of molecular variance (AMOVA) were also estimated using Arlequin 3.5 with 1000 permutations. In addition, the program SAMOVA (Dupanloup et al., 2002) was used to identify the groups that were maximally differentiated, i.e., those with a $K$ value (number of populations) from 2 to 6 , and to select the $K$ that resulted in the greatest variation among groups $\left(F_{\mathrm{CT}}\right)$.

The effective population size was evaluated using the LAMARC software (Kuhner and Smith, 2007). We ran the simulations under the coalescent model, based on a run of 10 short Markov chains with a sampling of 500 trees and 1 long chain with sampling of 10,000 trees. Three independent runs were performed to check the consistency of the results, and the profile likelihood for all parameters was evaluated at the 0.05 and 0.95 percentiles.

\section{Microsatellite genotyping and analysis}

Ten polymorphic microsatellite loci developed at our laboratory (Wang et al., 2010; Supplementary Table 1 ) were examined. The PCR mixture contained $1 \mu \mathrm{L}$ genomic DNA (20 $\mathrm{ng} / \mu \mathrm{L}), 5 \mu \mathrm{L}$ master mix $\left(0.2 \mu \mathrm{M}\right.$ dNTPs, $1.5 \mu \mathrm{M} \mathrm{MgCl}_{2}, 0.5 \mu \mathrm{M}$ Taq DNA polymerase $), 1$ $\mu \mathrm{L}$ primers $(0.5 \mu \mathrm{M}$ each), and $3 \mu \mathrm{L}$ distilled water. The PCR condition included an initial denaturation for $5 \mathrm{~min}$ at $94^{\circ} \mathrm{C}$, followed by 35 cycles of $94^{\circ} \mathrm{C}$ for $30 \mathrm{~s}, 55^{\circ} \mathrm{C}$ for $30 \mathrm{~s}, 72^{\circ} \mathrm{C}$ for $30 \mathrm{~s}$, and a final extension for $10 \mathrm{~min}$ at $72^{\circ} \mathrm{C}$. The PCR products were electrophoresed on $8 \%$ polyacrylamide gels and the fragment sizes $(\mathrm{bp})$ were recorded by Gel-PRO ANALYZER using PBR322 as a ladder marker.

Before statistical analysis, MICROCHECKER version 2.2.3 (Van Oosterhout et al., 2004) was used to test null alleles, stutter miscalls, and allelic dropout. The raw data matrix of the microsatellite alleles were established and filed in Microsoft Excel, and then transformed into the data format of FSTAT 2.9.4 (Goudet, 1995), GENEPOP 4.0 (Raymond and Rousset, 1995), Arlequin 3.5, and LAMARCK by means of CREATE, a specific file-creation/conversion software to create input files for 52 programs that analyze molecular data (Coombs et al., 2008).

Population genetic diversity was estimated by observed $\left(H_{\mathrm{O}}\right)$ and expected $\left(H_{\mathrm{E}}\right)$ heterozygosities, and inbreeding coefficient $\left(F_{\text {IS }}\right)$ using FSTAT version 2.9.3.2 (Goudet, 1995). Departure from Hardy-Weinberg equilibrium (HWE) of each locus in each population was tested using the Markov chain method implemented in GENEPOP version 4.0. Tests of significant genotypic disequilibrium between pairs of loci were also performed using FSTAT 2.9.3.2 on the basis of 4200 permutations after Bonferroni's corrections.

Genetic variability within a population and differentiation among populations were estimated using AMOVA and pairwise $F_{\mathrm{ST}}$ implemented in Arlequin 3.5. The SAMOVA program was also used to select the best groups with the greatest $F_{\mathrm{CT}}$. The effective population size was also estimated for each population by NeEstimator version 1.3 (Peel et al., 2004) using the microsatellite mutation model. Principal coordinate analysis (PCA) was performed on the basis of the standardized covariance matrix of genetic distances, by using GENALEX 6.4 (Peakall and Smouse, 2006).

The Bottleneck software (Piry et al., 1999) was used to examine whether each population experienced any genetic bottleneck events. We used the stepwise mutation model (SMM) and two-phased mutation model (TPM) for the analysis (Cornuet and Luikart, 1996) and performed 
the tests across 10,000 replications with 10\% variance for TPM, and 90, 95, and 98\% proportions of SMM in TPM. Statistical tests were performed using the Wilcoxon signed-rank test.

Microsatellites are believed to be selectively neutral. However, a neutral microsatellite may show apparent selective effects if it is in LD with other loci subject to selection (Barker et al., 2009). In this study, a hierarchical island model, which is based on the Beaumont test (Beaumont and Nichols, 1996), was used to detect the microsatellite loci under positive selection. Hierarchical analysis was separately conducted for the 4 domesticated strains, 2 wild populations, and all the 6 populations by using Arlequin 3.5 with 20,000 simulations.

\section{RESULTS}

\section{Mitochondrial DNA variation}

A total length of 826 bp was unambiguously aligned for the D-loop and 50 haplotypes were defined among the 239 individuals analyzed. These haplotypes were deposited in GenBank (HQ834905-HQ834946). The aligned sequences in the 2 wild population YZM and YZD were found to exhibit 39 and 40 polymorphic sites, respectively, resulting in 25 haplotypes each; however, only 3 (PR) and 12 (XG) polymorphic sites, resulting in only 2-5 haplotypes, were noted in the 4 domesticated strains (Table 1 and Figure 1). Private haplotypes were markedly higher in the wild populations (17 in YZD and 18 in YZM) than in the domesticated strains ( 3 in JIAN, 2 in XG, 1 in WA, no private haplotype in PR) (Figure 1). Conversely, a high frequency of shared haplotypes, ranging from 0.442 in JIAN to 0.959 in WA, was found in the domesticated strains. The haplotypic $(h)$ and nucleotide $(\pi)$ diversities were lower in the domesticated strains than in the wild populations (Table 1). Similarly, the estimated effective population sizes ( $\theta$ values), ranging from 0.0001 (WA) to 0.0003 (XG and JIAN), were considerably lower in the domesticated strains than in the wild populations.

\begin{tabular}{|c|c|c|c|c|c|c|c|c|c|c|c|c|c|}
\hline \multirow[t]{2}{*}{ Populations } & \multirow[t]{2}{*}{$N_{\mathrm{F}}$} & \multirow[t]{2}{*}{$N$} & \multicolumn{6}{|c|}{ mtDNA } & \multicolumn{5}{|c|}{ Microsatellite } \\
\hline & & & $S$ & $N_{\mathrm{P}}$ & $h$ & $\pi$ & $F_{\mathrm{ST}}$ & $\theta(95 \% \mathrm{CI})$ & $H_{\mathrm{o}}$ & $H_{\mathrm{E}}$ & $F_{\mathrm{IS}}$ & $F_{\text {ST }}$ & $N_{\mathrm{E}}$ \\
\hline YZD & Un & 32 & 40 & 25 & 0.9839 & 0.0105 & 0.4606 & $\begin{array}{c}0.0164 \\
(0.0089-0.0250)\end{array}$ & 0.8063 & 0.8392 & $\begin{array}{c}0.0399 \\
(\mathrm{P}=0.060)\end{array}$ & 0.0645 & $\begin{array}{c}506.9 \\
(166.7-\infty)\end{array}$ \\
\hline YZM & Un & 30 & 39 & 25 & 0.9885 & 0.0077 & 0.4683 & $\begin{array}{c}0.0243 \\
(0.0136-0.0416)\end{array}$ & 0.7967 & 0.8266 & $\begin{array}{c}0.0368 \\
(\mathrm{P}=0.069)\end{array}$ & 0.0647 & $\begin{array}{c}\infty \\
(231.9-\infty)\end{array}$ \\
\hline XG & 42 & 36 & 12 & 5 & 0.5048 & 0.0044 & 0.4775 & $\begin{array}{c}0.0003 \\
(0.0001-0.0009)\end{array}$ & 0.6833 & 0.7846 & $\begin{array}{c}0.1307 \\
(\mathrm{P}<0.001)\end{array}$ & 0.0653 & $\begin{array}{c}366.3 \\
(140.4-\infty)\end{array}$ \\
\hline WA & 4 & 49 & 11 & 3 & 0.0808 & 0.0005 & 0.4879 & $\begin{array}{c}0.0001 \\
(0.0000-0.0003)\end{array}$ & 0.6653 & 0.7530 & $\begin{array}{c}0.1175 \\
(\mathrm{P}<0.001)\end{array}$ & 0.0657 & $\begin{array}{c}44.1 \\
(36.9-53.8)\end{array}$ \\
\hline PR & 19 & 40 & 3 & 2 & 0.3577 & 0.0013 & 0.4858 & $\begin{array}{c}0.0002 \\
(0.0001-0.0007)\end{array}$ & 0.6525 & 0.7189 & $\begin{array}{c}0.0934 \\
(\mathrm{P}<0.001)\end{array}$ & 0.0663 & $\begin{array}{c}87.9 \\
(62.1-142.8)\end{array}$ \\
\hline JIAN & 8 & 52 & 15 & 4 & 0.6131 & 0.0068 & 0.4706 & $\begin{array}{c}0.0003 \\
(0.0002-0.0009)\end{array}$ & 0.7154 & 0.7681 & $\begin{array}{c}0.0693 \\
(\mathrm{P}<0.001)\end{array}$ & 0.0655 & $\begin{array}{c}65.6 \\
(53.1-83.8)\end{array}$ \\
\hline
\end{tabular}

$N_{\mathrm{F}}=$ number in founding population; $N=$ number of studied specimens; $S=$ Number of polymorphic sites; $N_{\mathrm{P}}=$ number of haplotypes; $h=$ haplotype diversity; $\pi=$ nucleotide diversity; $F_{\mathrm{ST}}=$ levels of differentiation within population; $\theta=$ effective population sizes from mtDNA data using the LARMAC program; $H_{\mathrm{O}}=$ mean observed heterozygosity of all loci; $H_{\mathrm{E}}=$ mean expected heterozygosity of all loci; $F_{\mathrm{IS}}=$ inbreeding coefficients; $N_{\mathrm{E}}=$ effective population sizes from microsatellite data using the NeEstimator program. $\mathrm{YZD}=$ Yangzhou in Jiangsu; YZM = Shishou in Hubei; XG = Xingguo red common carp; WA = glass red common carp; $\mathrm{PR}=$ pursed red common carp; JIAN = Jian common carp; Un = unknown.. 


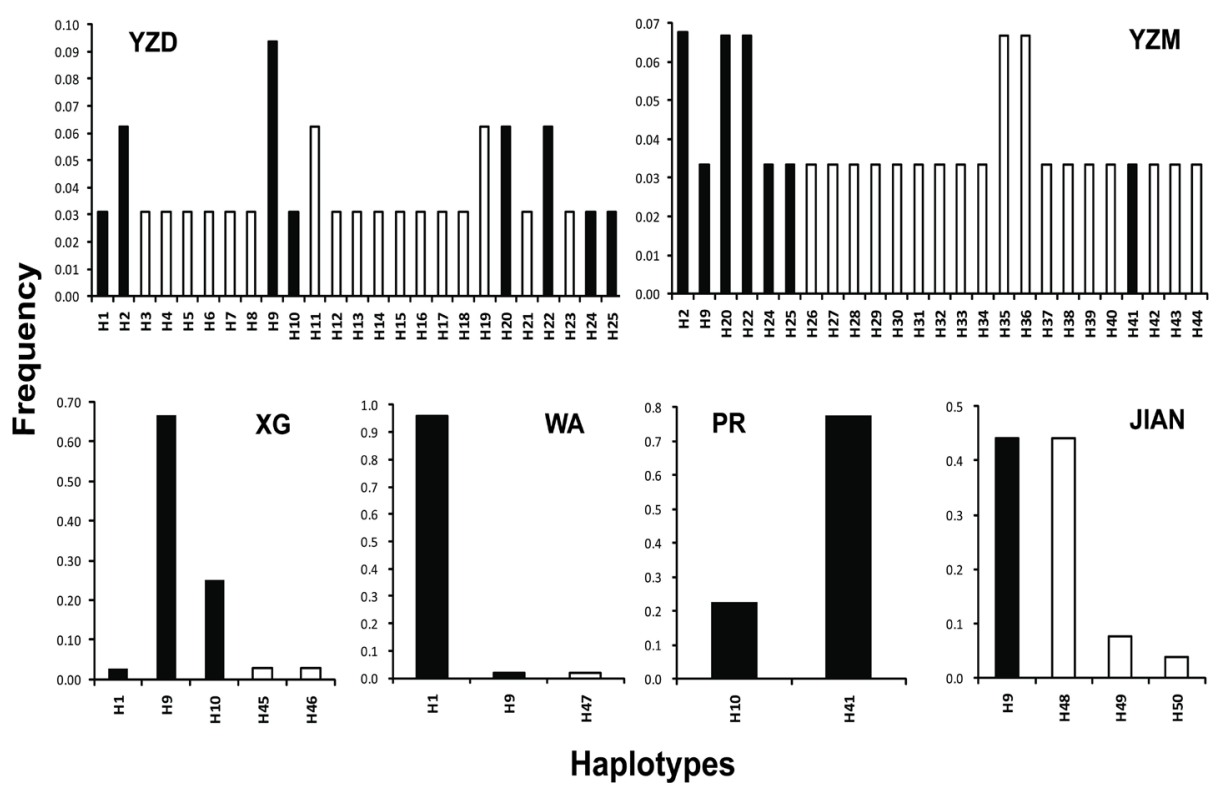

Figure 1. Frequency distribution of mtDNA haplotypes in the two wild populations (upper row) and the four domesticated strains (lower row). Filled bars represent shared haplotypes among all populations, open bars show the private haplotypes in each population. For abbreviations, see legend to Table 1.

The results of AMOVA analysis indicated that there was a non-significant difference between the wild and domesticated common carps, with negative fixation indices (Table 2). However, SAMOVA analysis revealed that 4 groups, namely, 2 wild populations and XG as 1 group and the remaining 3 domesticated populations as 3 other groups, maximized the $F_{\mathrm{CT}}$, accounting for $34.38 \%$ of the total variation (Table 2). Pairwise $F_{\mathrm{ST}}$ values between populations ranged from 0.0953 between YZD and YZM to 0.9005 between WA and PR. The domesticated strain WA had the largest $F_{\mathrm{ST}}$ values $\left(0.5427-0.9005\right.$, mean $\left.F_{\mathrm{ST}}=0.6968\right)$ with the other populations (Table 3).

Table 2. Percentage of variation and fixation indices from AMOVA and SAMOVA with the largest variation among groups $\left(F_{\mathrm{CT}}\right)$ from mtDNA and microsatellite data.

\begin{tabular}{|c|c|c|c|c|}
\hline \multirow[t]{2}{*}{ Sources of variation } & \multicolumn{2}{|r|}{ mtDNA } & \multicolumn{2}{|c|}{ Microsatellite } \\
\hline & $\begin{array}{l}\text { Percentage of } \\
\text { variation }\end{array}$ & Fixation indices & $\begin{array}{l}\text { Percentage of } \\
\text { variation }\end{array}$ & Fixation indices \\
\hline \multicolumn{5}{|l|}{ AMOVA: no group } \\
\hline Among populations & 47.61 & $F_{\mathrm{ST}}=0.4761(\mathrm{P}<0.01)$ & 6.54 & $F_{\mathrm{ST}}=0.0654(\mathrm{P}<0.01)$ \\
\hline Within populaitons & 52.39 & & 93.46 & \\
\hline \multicolumn{5}{|c|}{ AMOVA: 2 groups (wild $v s$ domesticated) } \\
\hline Among groups & -12.63 & $F_{\mathrm{CT}}=-0.1263(\mathrm{P}=1.000)$ & -2.34 & $F_{\mathrm{CT}}=-0.0140(\mathrm{P}=0.807)$ \\
\hline Among populations within groups & 56.70 & $F_{\mathrm{SC}}^{\mathrm{CT}}=0.5034(\mathrm{P}<0.001)$ & 13.15 & $F_{\mathrm{SC}}^{\mathrm{CT}}=0.0714(\mathrm{P}<0.001)$ \\
\hline Within populations & 55.93 & $F_{\mathrm{ST}}^{\mathrm{SC}}=0.4407(\mathrm{P}<0.001)$ & 89.19 & $F_{\mathrm{ST}}^{\mathrm{SC}}=0.0584(\mathrm{P}<0.001)$ \\
\hline \multicolumn{5}{|c|}{ SAMOVA: 4 groups (YZM+YZD+XG; PR; WA; JIAN) } \\
\hline Among groups & 34.38 & $F_{\mathrm{CT}}=0.3438(\mathrm{P}=0.025)$ & 8.51 & $F_{\mathrm{CT}}=0.0851(\mathrm{P}=0.048)$ \\
\hline Among populations within groups & 15.39 & $F_{\mathrm{SC}}=0.2346(\mathrm{P}<0.001)$ & 4.73 & $F_{\mathrm{SC}}=0.0517(\mathrm{P}<0.001)$ \\
\hline Within populations & 50.23 & $F_{\mathrm{ST}}^{\mathrm{sc}}=0.4977(\mathrm{P}<0.001)$ & 86.76 & $F_{\mathrm{ST}}^{\mathrm{sc}}=0.1324(\mathrm{P}<0.001)$ \\
\hline
\end{tabular}

For abbreviations, see legend to Table 1. 
Table 3. Pairwise $F_{\mathrm{ST}}$ values for domesticated and wild common carps based on microsatellite loci (below diagonal) and mtDNA sequences (above diagonal).

\begin{tabular}{|c|c|c|c|c|c|c|}
\hline Populations & YZD & YZM & $\mathrm{XG}$ & WA & PR & JIAN \\
\hline YZD & & $0.0953 * *$ & $0.2666 * *$ & $0.5427 * *$ & $0.4359 * *$ & $0.1767 * *$ \\
\hline YZM & $0.0014^{\mathrm{NS}}$ & & $0.2716^{* *}$ & $0.6100 * *$ & $0.3222 * *$ & $0.2117^{* *}$ \\
\hline $\mathrm{XG}$ & $0.0244 * *$ & $0.0256^{* *}$ & & $0.7721 * *$ & $0.6332 * *$ & $0.2300^{* *}$ \\
\hline WA & $0.0509^{* *}$ & $0.0592 * *$ & $0.0628 * *$ & & $0.9005^{* *}$ & $0.6587 * *$ \\
\hline PR & $0.0838 * *$ & $0.0589 * *$ & $0.1160 * *$ & $0.1197^{* *}$ & & $0.5449^{*}$ \\
\hline JIAN & $0.0390^{* *}$ & $0.0298 * *$ & $0.0694 * *$ & $0.0968 * *$ & $0.0670 * *$ & \\
\hline
\end{tabular}

$* * \mathrm{P}<0.01 ; * \mathrm{P}<0.05 ; \mathrm{NS}=$ not significant $(\mathrm{P}>0.05)$. For abbreviations, see legend to Table 1.

\section{Microsatellite variation}

No significant results were obtained for tests of null alleles, stutter miscalls, and allelic dropout in each population by using the MicroChecker program. All 10 microsatellite loci were polymorphic, and a total of 128 alleles were observed within the 6 populations, with number of alleles across the loci varying from 4 to 17. In the wild populations, 1 locus in YZM and 2 loci in YZD deviated significantly from the HWE, whereas in the domesticated populations, the number of such loci ranged from 3 (JIAN) to 5 (WA). Two (YZD, YZM) to 13 (WA) pairs of loci were observed in LD but no comparison was found to be significant after sequential Bonferroni's correction. The number of private alleles was low in all 6 populations (2-9 in wild populations and 1-3 in domesticated strains).

Genetic variations within populations, indicated by $H_{\mathrm{O}}$ and $H_{\mathrm{E}}$, were lower in the domesticated strains than the wild populations (Table 1$)$. Conversely, inbreeding coefficients $\left(F_{\text {IS }}\right)$ calculated from the domesticated strains $(0.0693-0.1307)$ were higher than those for the wild populations (0.0369-0.0399) (Table 1). No significant differences were noted between the pooled wild and pooled domesticated populations in the above mentioned genetic variation indices and inbreeding coefficients. However, the domesticated populations demonstrated higher $F_{\mathrm{ST}}$ values within themselves than the wild populations. The effective number of estimations ranged from 44.1 in WA to 366.3 in XG, as determined using the NeEstimator software (Table 1). No evidence for a recent genetic bottleneck was found in any of the 6 populations, as verified by using SMM and TPM model tests implemented in the Bottleneck software.

Analysis of genetic differentiation among populations using AMOVA revealed no significant differentiation between the pooled domesticated strains and pooled wild populations $\left(F_{\mathrm{CT}}=-0.0140, \mathrm{P}=0.807\right.$; Table 2$)$. However, the largest values $\left(F_{\mathrm{CT}}=0.0851, \mathrm{P}=0.048\right)$ among populations were found when 4 groups were defined using the SAMOVA program, mirroring the results of the mtDNA analysis. Pairwise $F_{\mathrm{ST}}$ values were significantly different from 0 , with the exception of the 2 wild populations (YZD and YZM; Table 3 ). The results of principal component analysis revealed an obvious separation between the domesticated and wild populations, especially among the 4 domesticated strains (Figure 2).

Hierarchical analysis revealed marked differentiation between the domesticated and wild populations. In the domesticated strains, 2 loci (CL029 and CL041) fell outside the 99\% quantile limit and 3 loci (CL055, CL058, and CL043) fell within the 95-99\% quantile limit (Figure $3 \mathrm{~A}$ ), indicating that these 5 loci were candidates for positive artificial selection. In the wild populations, all 10 loci fell within the 95\% quantile limit (Figure 3B), demonstrating that they were candidates for balancing selection. When combining the domesticated and 
wild populations (6 populations), only 1 locus (CL029) fell within the 95-99\% quantile limit and the remaining loci were located in the 5-95\% quantile limits (Figure 3C), indicating that balancing selection predominated in the combined population.

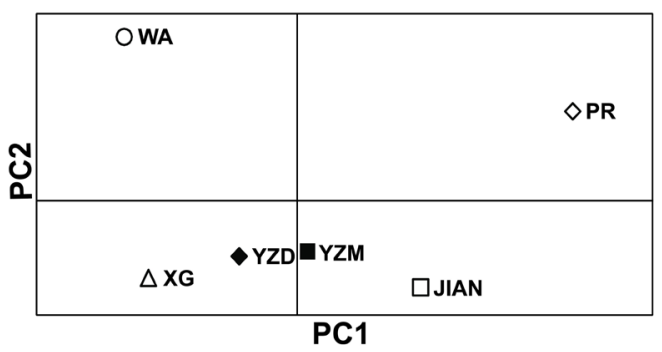

Figure 2. Principal component (PC) analysis based on microsatellite data for 6 populations of common carp. For abbreviations, see legend to Table 1 .

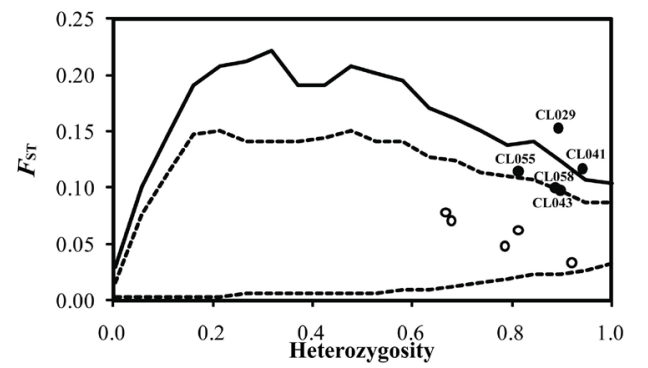

A

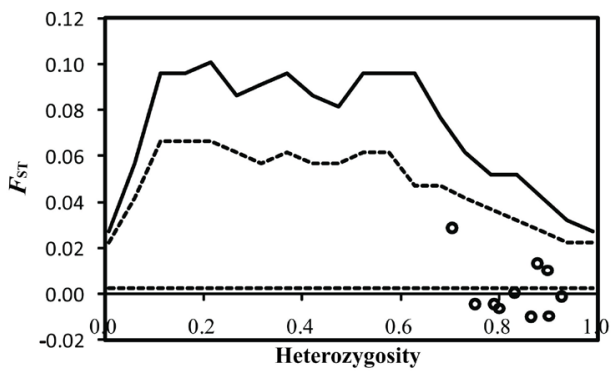

B

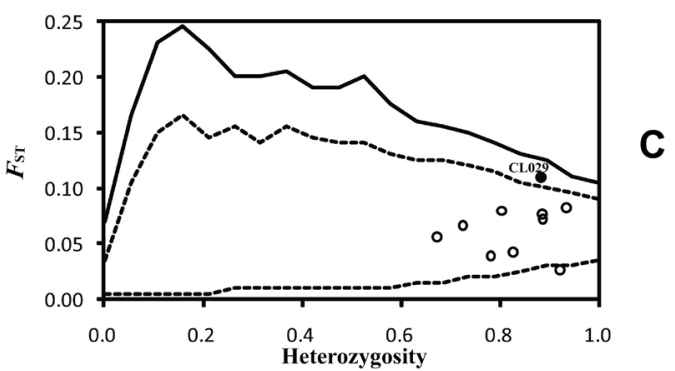

Figure 3. Plots of the $F_{\mathrm{ST}}$ values against heterozygosity in 10 microsatellite loci for the domesticated strains (A), wild populations (B) and all the six populations (C). Solid lines represent $99 \%$ quantile limits, dashed lines denote 95 and $5 \%$ quantile limits. Black dots are candidate loci under positive selection and white dots are candidate loci under balancing selection. 


\section{Variation correlation between mtDNA and microsatellite}

The $F_{\mathrm{ST}}$ values in mtDNA (mean $F_{\mathrm{CT}}=0.4448$, size $=0.0953-0.9005$ ) were considerably higher than those in microsatellites (mean $F_{\mathrm{CT}}=0.0603$, size $=0.0014-0.1197$ ). Significant linear correlations were detected between $F_{\mathrm{ST}}$ values in microsatellite and in mtDNA (Figure 4).

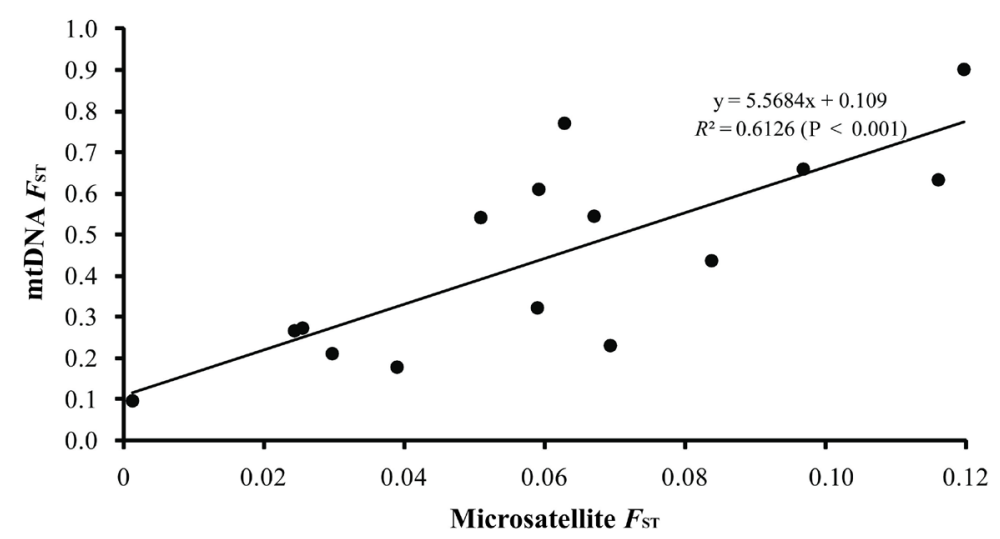

Figure 4. Correlation between $F_{\mathrm{ST}}$ values from microsatellite versus mtDNA data in the six populations of common carp.

\section{DISCUSSION}

\section{Genetic diversity within populations}

Domesticated species are known to have less genetic variation than their wild conspecifics because of population bottlenecks, founder effects, and artificial selection during domestication (Innan and Kim, 2004). A large body of literature has documented the loss of genetic diversity in domesticated populations, unlike wild populations; examples of such domesticated populations include Tinca tinca (Kohlmann et al., 2007), Haliotis discus (Li et al., 2007), Cirrhinus cirrhosus (Aung et al., 2010), and C. carpio (Kohlmann et al., 2005; Chistiakov and Voronova, 2009; Wang et al., 2010). In the present study, the 4 domesticated strains have been subjected to selection on the basis of growth rate (e.g., body weight, standard length, and body height) for about 20 generations (40 years). They all have been subjected to continuous selection pressures during genetic improvement. Thus, the domesticated strains showed lower inter-strain genetic diversity compared to wild populations, although no statistical difference was observed in the pooled groups. This implicated that a bottleneck event could have occurred in the domesticated strains. However, no significant signature of bottleneck effects was found in any of the 4 domesticated strains using TPM and SMM model tests implemented in the Bottleneck program. This can be explained by the fact that artificial selective mutation is considerably different from natural mutation; these 2 models may not be appropriate for the bottleneck analysis of domesticated populations that have diverged through strong artificial selection. In addition, rapid genetic changes from artificial selection to fix the desired phenotypes would have compensated for some loss of genetic variation, and this was confirmed by the presence of private haplotypes and alleles in each domesticated strain. 
Genetic diversity is greatly influenced by founder population sizes in common carp (Chistiakov and Voronova, 2009). In the domesticated strains, the founder population sizes were well documented. XG were founded initially by artificial selection in 1972 with 42 individuals and PR in 1969 with 19 individuals. WA, which were occasionally found in 1963, was founded from 4 mutant juveniles of wild common carp in the Yangtze River (Lou and Sun, 2001). These 3 common carp strains have been subjected to mass selection during domestic breeding. The last domesticated strain, JIAN, was developed in about 1978 from 4 crossing families between the PR (female) and Yuanjiang wild common carp (male), by using combined breeding techniques of family selection, interline crossing, gynogenesis, and mass selection during artificial domestication (Zhang and Sun, 2006). The genetic variation in the present study is consistent with the founder population size, especially in XG, PR, and WA, although no statistically significant correlations between the founder population sizes and genetic diversity were found by haplotype and nucleotide diversities in mtDNA or $H_{\mathrm{O}}$ and $H_{\mathrm{E}}$ in microsatellites. The WA strain showed the lowest genetic diversity and the lowest simulated effective population sizes ( 0.0001 in mtDNA and 44.1 in microsatellite) (Table 1). The results indicated that the current genetic diversity in the domesticated strains was partially influenced by the founder population numbers. Furthermore, artificial selection in the domestication or improvement process exerts its effects on a haplotype or allele, and creates a dramatic change in the frequency of the haplotype or allele. Alternatively, artificial selection can cause some haplotypes and alleles, which were neutral polymorphisms in the progenitor strains, to become very advantageous after domestication, and this was confirmed by the haplotype frequency distribution (Figure 1). Thus, the loss of genetic diversity in the 4 domesticated strains mainly resulted from artificial selection, especially artificial directional selection during the process of domestication or improvement. On the other hand, environmental isolation and genetic drift during domestication process would have contributed to population variation to some extent.

In contrast to XG, PR, and WA, the JIAN strain surprisingly showed higher genetic diversity, although it had the second lowest founder population size (4 families, 8 individuals). This is probably because of the shortest domestication history and hybridization background of this strain. Moreover, relatively low artificial selection pressure and inbreeding level $\left(F_{\text {IS }}=\right.$ 0.0693 , Table 1) would have sustained the genetic diversity in this species.

In view of the larger effective population sizes $\left(\theta=0.0164-0.0243\right.$ in mtDNA and $N_{\mathrm{E}}$ $=506.9-\infty$ in microsatellite; Table 1$)$ and natural balancing selection, it is clear that the 2 wild populations displayed higher genetic diversities than the domesticated strains.

\section{Genetic difference among populations}

Significant genetic divergence has been reported between the wild and domesticated populations of many aquatic species (Appio and Weber, 2007). In our study, there was a significantly higher genetic divergence between the wild and domesticated populations, and among the domesticated populations, with the exception of YZD and YZM (Table 3). This conclusion was also supported by the results of principal component analysis (Figure 2). The low genetic differentiation between the 2 wild populations can be attributed to the gene flow between them since they inhabit the same river and are subject to balancing selection under natural conditions. It is well accepted that high genetic divergence between the wild and domesticated populations and among domesticated strains, is due to positive selection, in particular, strong artificial selection (Barker et al., 2009). 
The WA and PR strains showed considerably higher genetic divergence than the other populations (Table 3 and Figure 2), possibly due to the very small founder populations (4 individuals in WA and 19 individuals in PR) and genetic drift during domestication or the improvement process. The relatively moderate levels of genetic divergence among the remaining 4 populations could have resulted from the relatively large founder populations (e.g., 42 in $\mathrm{XG})$ and a hybridization breeding strategy employed in JIAN.

The strongly significant correlation between $F_{\mathrm{ST}}$ in mtDNA and in microsatellite loci (Figure 4) suggested similar trends in genetic variability in the mtDNA and SSR data, confirming directional positive selection on the domesticated strains.

\section{Artificial selection sweeps}

Selection, including positive natural selection and artificial selection, can lead to reduced genetic diversity within a population and increased genetic differentiation between populations. The $F_{\mathrm{ST}}$ value between populations is widely believed to indicate selective sweep (Vigouroux et al., 2002; Hansen et al., 2010). Negative or balancing selection tends to decrease $F_{\mathrm{ST}}$, whereas local positive selection tends to increase $F_{\mathrm{ST}}$ (Nielsen, 2005). In the present study, we found these signatures of selection effects in both the wild and domesticated populations. The high level of haplotype and nucleotide diversities, low inbreeding coefficients and interpopulation $F_{\mathrm{ST}}$ (Table 1), non-significant pairwise $F_{\mathrm{ST}}$ value (Table 3 ), and even haplotype frequency distribution in mtDNA (Figure 1) indicated relative balancing selection in the wild populations under natural condition. Hierarchical analysis (Figure 3) also confirmed the influence of balancing selection on the wild populations. In contrast, the highly significant $F_{\text {ST }}$ values between strains and low genetic variability within strains, accompanied by a sharp distribution of mtDNA haplotypes and detected microsatellite loci under selection, indicated the influence of positive artificial selection on the domesticated strains.

Many studies have illustrated that directional selection promotes LD or that it results in significant LD (Excoffier et al., 2009; Rogell et al., 2010). In the present study, a higher level of LD between loci was found in the domesticated strains than in the wild populations, suggesting directional selection in the domesticated strains.

Recently, selection pressures on mitochondrial DNA have been widely reported (Bazin et al., 2006; Galtier et al., 2009). Due to the hitchhiking effects, a microsatellite may show directional selection. Several reports have described selection sweeps on microsatellites (Kauer et al., 2003; Barker et al., 2009). Microsatellites are reported to be a better predictor of genomic-wide genetic diversity than SNPs (Ljungqvist et al., 2010). Some approaches have been proposed to detect specific microsatellite loci under selection; examples include the Beaumont test (Beaumont and Nichols, 1996), the Bayesian simulation-based test (Beaumont and Balding, 2004), and hierarchical model tests (Excoffier and Lischer, 2010). In our study, using the hierarchical model test based on the Beaumont test, we found artificial selective sweeps in the domesticated strains (Figure 3).

\section{Implications of genetic management}

Initial genetic variation is the key to improving a stock through selective breeding programs (Rahman et al., 2009). At a population level, a reduction in the number of alleles 
observed at microsatellite loci can be indicative of a loss of potentially important functional genetic variation in other regions of the genome, and its avoidance should be considered a priority in aquaculture (Lind et al., 2009). Wild populations represent the primary source of genetic variability for aquaculture stocks; therefore, it is very important to maintain genetic diversity of domesticated strains and minimize its negative effects on wild populations. Thus, it is necessary to prevent or monitor escapees of domesticated strains for introgression into the genetic pool of wild populations. Additionally, a program to maintain the genetic diversity of domesticated strains, especially glass red common carp, is imperative.

\section{ACKNOWLEDGMENTS}

Research supported by the Special Fund for Agro-Scientific Research in the Public Interest (\#200903045), the Program for New Century Excellent Talents in University (\#NCET08-0896) and the Zhejiang Provincial Project of Science and Technology (\#2010C32088).

\section{REFERENCES}

Appio KT and Weber LI (2007). Temporal genetic differentiation in cultured and natural beds of the brown mussel Perna perna (Mytilidae). Genet. Mol. Res. 6: 127-136.

Aung O, Nguyen TTT, Poompuang S and Kamonrat W (2010). Microsatellite DNA markers revealed genetic population structure among captive stocks and wild populations of mrigal, Cirrhinus cirrhosus in Myanmar. Aquaculture 299: 37-43.

Balon E (1995). Origin and domestication of the wild carp, Cyprinus carpio: from Roman gourmets to the swimming flowers. Aquaculture 129: 3-48.

Barker JSF, Frydenberg J, González J, Davies HI, et al. (2009). Bottlenecks, population differentiation and apparent selection at microsatellite loci in Australian Drosophila buzzatii. Heredity 102: 389-401.

Bazin E, Glemin S and Galtier N (2006). Population size does not influence mitochondrial genetic diversity in animals. Science 312: 570-572.

Beaumont MA and Nichols RA (1996). Evaluating loci for use in the genetic analysis of population structure. Proc. R. Soc. Lond. B 263: 1619-1626.

Beaumont MA and Balding DJ (2004). Identifying adaptive genetic divergence among populations from genome scans. Mol. Ecol. 13: 969-980.

Carlson SM, Edeline E, Asbjorn VL, Haugen TO, et al. (2007). Four decades of opposing natural and human-induced artificial selection acting on Windermere pike (Esox lucius). Ecol. Lett. 10: 512-521.

Cheng Y, Wakefield M, Siddle HV, Coggill PC, et al. (2009). Isolation and characterization of $10 \mathrm{MHC}$ Class I-associated microsatellite loci in tammar wallaby (Macropus eugenii). Mol. Ecol. Resour. 9: 346-349.

Chistiakov DA and Voronova NV (2009). Genetic evolution and diversity of common carp Cyprinus carpio L. Cent. Eur. J. Biol. 4: 304-312.

Coombs JA, Letcher BH and Nislow KH (2008). CREATE: a software to create input files from diploid genotypic data for 52 genetic software programs. Mol. Ecol. Resour. 8: 578-580.

Cornuet JM and Luikart G (1996). Description and power analysis of two tests for detecting recent population bottlenecks from allele frequency data. Genetics 144: 2001-2014.

Dupanloup I, Schneider S and Excoffier L (2002). A simulated annealing approach to define the genetic structure of populations. Mol. Ecol. 11: 2571-2581.

Excoffier L and Lischer HEL (2010). Arlequin suite ver 3.5: a new series of programs to perform population genetics analyses under Linux and Windows. Mol. Ecol. Resour. 10: 564-567.

Excoffier L, Hofer T and Foll M (2009). Detecting loci under selection in a hierarchically structured population. Heredity 103: 285-298.

Fraser DJ, Cook AM, Eddington JD, Bentzen P, et al. (2008). Mixed evidence for reduced local adaptation in wild salmon resulting from interbreeding with escaped farmed salmon: complexities in hybrid fitness. Evol. Appl. 1: 501-512.

Galtier N, Nabholz B, Glemin S and Hurst GD (2009). Mitochondrial DNA as a marker of molecular diversity: a reappraisal. Mol. Ecol. 18: 4541-4550.

Goudet J (1995). FSTAT (Version 1.2): A computer program to calculate $F$-statistics. J. Heredity 86: 485-486.

Genetics and Molecular Research 11 (3): 3222-3235 (2012)

CFUNPEC-RP www.funpecrp.com.br 
Hall TA (1999). BioEdit: A user-friendly biological sequence alignment editor and analysis program for Windows 95/98/ NT. Nucleic Acids Symp. Ser. 41: 95-98.

Hansen MM, Meier K and Mensberg KLD (2010). Identifying footprints of selection in stocked brown trout populations: a spatio-temporal approach. Mol. Ecol. 19: 1787-1800.

Innan H and Kim Y (2004). Pattern of polymorphism after strong artificial selection in a domestication event. Proc. Natl. Acad. Sci. U. S. A. 101: 10667-10672.

Kauer MO, Dieringer D and Schlotterer C (2003). A microsatellite variability screen for positive selection associated with the "out of Africa" habitat expansion of Drosophila melanogaster. Genetics 165: 1137-1148.

Kohlmann K, Kersten P and Flajšhans M (2005). Microsatellite-based genetic variability and differentiation of domesticated, wild and feral common carp (Cyprinus carpio L.) populations. Aquaculture 247: 253-266.

Kohlmann K, Kersten P and Flajshans M (2007). Comparison of microsatellite variability in wild and cultured tench (Tinca tinca). Aquaculture 272: S147-S151.

Kuhner MK and Smith LP (2007). Comparing likelihood and Bayesian coalescent estimation of population parameters. Genetics 175: 155-165.

Li Q, Shu J, Yu RH and Tian CY (2007). Genetic variability of cultured populations of the Pacific abalone (Haliotis discus hannai Ino) in China based on microsatellites. Aquac. Res. 38: 981-990.

Lind CE, Evans BS, Knauer J, Taylor JJU, et al. (2009). Decreased genetic diversity and a reduced effective population size in cultured silver-lipped pearl oysters (Pinctada maxima). Aquaculture 286: 12-19.

Ljungqvist M, Åkesson M and Hansson B (2010). Do microsatellites reflect genome-wide genetic diversity in natural populations? Mol. Ecol. 19: 851-855.

Lou YD and Sun JC (2001). Progress on studies of origin and genetic diversity of three breeds of red carp in Jiangxi province. J. Fish. China 25: 570-575.

McGinnity P, Prodohl P, Ferguson A, Hynes R, et al. (2003). Fitness reduction and potential extinction of wild populations of Atlantic salmon, Salmo salar, as a result of interactions with escaped farm salmon. Proc. Biol. Sci. 270: 2443-2450.

Nei M (1987). Molecular Evolution Genetics. Columbia University Press, New York.

Nielsen R (2005). Molecular signatures of natural selection. Annu. Rev. Genet. 39: 197-218.

Peakall R and Smouse PE (2006). GENALEX 6: genetic analysis in Excel. Population genetic software for teaching and research. Mol. Ecol. Notes 6: 288-295.

Peel D, Ovenden JR and Peel SL (2004). NeEstimator: Software for Estimating Effective Population Size. Version 1.3. Department of Primary Industries and Fisheries, Queensland Government, Brisbane.

Piry S, Luikart G and Cornuet JM (1999). BOTTLENECK: a computer program for detecting recent reductions in the effective size using allele frequency data. J. Heredity 90: 502-503.

Posada D (2006). Collapse: Describing Haplotypes from Sequence Alignments. In: Computational Evolutionary Biology Laboratory, University of Vigo, Vigo.

Rahman SMZ, Khan MR, Islam S and Alam S (2009). Genetic variation of wild and hatchery populations of the catla Indian major carp (Catla catla Hamilton 1822: Cypriniformes, Cyprinidae) revealed by RAPD markers. Genet. Mol. Biol. 32: 197-201.

Raymond M and Rousset F (1995). GENEPOP (version 1.2): Population genetics software for exact tests and ecumenicism. Heredity 86: 248-249.

Rogell B, Eklund M, Thorngren H, Laurila A, et al. (2010). The effects of selection, drift and genetic variation on lifehistory trait divergence among insular populations of natterjack toad, Bufo calamita. Mol. Ecol. 19: 2229-2240.

Sambrook Jl and Russell DW (2001). Molecular Cloning: A Laboratory Manual. Cold Spring Harbor Laboratory Press, New York.

Van Oosterhout C, Hutchinson WF, Wills DPM and Shipley P (2004). MICRO-CHECKER: software for identifying and correcting genotyping errors in microsatellite data. Mol. Ecol. Notes 4: 535-538.

Vigouroux Y, McMullen M, Hittinger CT, Houchins K, et al. (2002). Identifying genes of agronomic importance in maize by screening microsatellites for evidence of selection during domestication. Proc. Natl. Acad. Sci. U. S. A. 99: 96509655.

Wang CH, Li SF, Nagy ZT, Lehoczky I, et al. (2010). Molecular genetic structure and relationship of Chinese and Hungarian common carp (Cyprinus carpio L.) strains based on mitochondrial sequence. Aquac. Res. 41: 1339-1347.

Zhang JS and Sun XY (2006). Open and analysis of breeding techniques for Jian common carp. China Fish. 9: 69-72. 


\section{SUPPLEMENTARY MATERIAL}

\begin{tabular}{|c|c|c|c|c|}
\hline Locus & GenBank No. & Primer sequence $\left(5^{\prime} \rightarrow 3^{\prime}\right)$ & $\mathrm{T}_{\mathrm{m}}\left({ }^{\circ} \mathrm{C}\right)$ & Size (bp) \\
\hline CL004 & JF825146 & $\begin{array}{l}\text { F: GGGAACGGCTCTCTGTTA } \\
\text { R: CTTCAGGGGCTTCTTTTGTG }\end{array}$ & 62 & 191 \\
\hline CL010 & JF825147 & $\begin{array}{l}\text { F: GGGCTTTCAGGTCACATACA } \\
\text { R: ACAGTTCCACCAAACACTGG }\end{array}$ & 61 & 195 \\
\hline CL018 & JF825148 & $\begin{array}{l}\text { F: TGCAGCATCTGTCTCACTCA } \\
\text { R: TAGCTGGTCCTTCCTTCTCA }\end{array}$ & 62 & 155 \\
\hline CL022 & JF825149 & $\begin{array}{l}\text { F: AACAGCAGGAGGGAAACGA } \\
\text { R: CTATACATGTGGCAAGCGGT }\end{array}$ & 56 & 197 \\
\hline CL029 & JF825150 & $\begin{array}{l}\text { F: GCCAAGAGACAACAATTCTGA } \\
\text { R: GCCACTGGAATTTCTATCACG }\end{array}$ & 53 & 160 \\
\hline CL041 & JF825151 & $\begin{array}{l}\text { F: CCTACTGCTCTGTCAGTCGAT } \\
\text { R: GAACCATGGTAGCACCACTT }\end{array}$ & 60 & 202 \\
\hline CL043 & JF825152 & $\begin{array}{l}\text { F: AGCCTGTGTGCTGAACAGTT } \\
\text { R: TGCTCTGAAGTCATTCTCCC }\end{array}$ & 60 & 215 \\
\hline CL046 & JF825154 & $\begin{array}{l}\text { F: GAAGAGATGCAGCAGCAAGT } \\
\text { R: TCAGTCTGCACTCAGATGCA }\end{array}$ & 60 & 161 \\
\hline CL055 & JF825153 & $\begin{array}{l}\text { F: CTGTAGGTTGCTAGGGCATT } \\
\text { R: ACCGAGAAGGCAGAAGGTAT }\end{array}$ & 61 & 153 \\
\hline CL058 & JF825155 & $\begin{array}{l}\text { F: GCAGGTATTGTAATAGTGCCA } \\
\text { R: CTCAGTTTGAAAAACTGACCC }\end{array}$ & 58 & 160 \\
\hline
\end{tabular}

$\mathrm{F}=$ forward primer; $\mathrm{R}=$ reverse primer; $\mathrm{T}_{\mathrm{m}}=$ melting temperature. 